Article

\title{
Biochemical and Structural Characterization of Cross-Linked Enzyme Aggregates (CLEAs) of Organic Solvent Tolerant Protease
}

\author{
Muhammad Syafiq Mohd Razib ${ }^{1,2}$, Raja Noor Zaliha Raja Abd Rahman 1,3(1), \\ Fairolniza Mohd Shariff ${ }^{1,3}$ and Mohd Shukuri Mohamad Ali ${ }^{1,2, *}$ \\ 1 Enzyme and Microbial Technology Research Centre, Faculty of Biotechnology and Biomolecular Sciences, \\ Universiti Putra Malaysia, UPM Serdang, Selangor 43400, Malaysia; syafiqrazib93@gmail.com (M.S.M.R.); \\ rnzaliha@upm.edu.my (R.N.Z.R.A.R.); fairolniza@upm.edu.my (F.M.S.) \\ 2 Department of Biochemistry, Faculty of Biotechnology and Biomolecular Sciences, Universiti Putra Malaysia, \\ UPM Serdang, Selangor 43400, Malaysia \\ 3 Department of Microbiology, Faculty of Biotechnology and Biomolecular Sciences, Universiti Putra Malaysia, \\ UPM Serdang, Selangor 43400, Malaysia \\ * Correspondence: mshukuri@upm.edu.my; Tel.: +60-3-9769-6721
}

Received: 30 September 2019; Accepted: 13 November 2019; Published: 1 January 2020

\begin{abstract}
Cross-linked enzyme aggregates (CLEAs) is an immobilization technique that can be used to customize enzymes under an optimized condition. Structural analysis on any enzyme treated with a CLEA remains elusive and has been less explored. In the present work, a method for preparing an organic solvent tolerant protease using a CLEA is disclosed and optimized for better biochemical properties, followed by an analysis of the structure of this CLEA-treated protease. The said organic solvent tolerant protease is a metalloprotease known as elastase strain $\mathrm{K}$ in which activity of the metalloprotease is measured by a biochemical interaction with azocasein. Results showed that when a glutaraldehyde of $0.02 \%(v / v)$ was used under a $2 \mathrm{~h}$ treatment, the amount of recovered activity in CLEA-elastase was highest. The recovered activity of CLEA-elastase and CLEA-elastase-SB (which was a CLEA co-aggregated with starch and bovine serum albumin (BSA)) were at an approximate $60 \%$ and $80 \%$, respectively. The CLEA immobilization of elastase strain $\mathrm{K}$ allowed the stability of the enzyme to be enhanced at high temperature and at a broader $\mathrm{pH}$. Both CLEA-elastase and CLEA-elastase-SB end-products were able to maintain up to $67 \%$ enzyme activity at $60{ }^{\circ} \mathrm{C}$ and exhibiting an enhanced stability within $\mathrm{pH} 5-9$ with up to $90 \%$ recovering activity. By implementing a CLEA on the organic solvent tolerant protease, the characteristics of the organic solvent tolerant were preserved and enhanced with the presence of $25 \%(v / v)$ acetonitrile, ethanol, and benzene at $165 \%, 173 \%$, and $153 \%$ relative activity. Structural analysis through SEM and dynamic light scattering (DLS) showed that CLEA-elastase had a random aggregate morphology with an average diameter of $1497 \mathrm{~nm}$.
\end{abstract}

Keywords: CLEA; solvent-tolerant protease; glutaraldehyde; immobilization

\section{Introduction}

Enzymes are considered one of the most notable biocatalysts and are extensively used in the industry considering its wide applications and advantages. Generally, the use of enzymes in industrial bioprocesses is desirable as enzymes offer a greener alternative to chemical catalysts when taking into consideration biodegradability, cost-effectiveness and the production of non-toxic byproducts [1]. The enzymes in this group, which include protease, lipase, and amylase, have been commonly used as biocatalysts in the industry for many years. More particularly, an enzyme such as protease is known 
for its application in detergent, mostly in removing protein-based stains, leather industry that involves hair removal, and various food productions. However, there is a major shortfall in using enzymes as biocatalysts which is related to their tendency to denature under any extreme conditions. For example, protease is susceptible to oxidation and autolysis when kept over a period of time [2-4]. Other extreme conditions that may affect the stability of protease include extreme temperature, $\mathrm{pH}$, and organic solvents which may be present in the reaction media [5,6]. Organic solvents are used in the reaction media to shift the catalytic reaction towards the completion of synthesis in a one-phase or two-phase system. Organic solvents can be classified according to their $\log P_{o / w}$ value, where any organic solvent showing $\log P_{o / w}<2$ is a polar organic solvent and any organic solvent showing $\log P_{o / w}>4$ is a non-polar organic solvent [7-9].

The presence of an organic solvent in the reaction media is detrimental to enzymes because organic solvents alter the hydrophobicity of the medium and affect the bonding and conformational structure of the enzyme. The changes in conformational structure of the enzyme can lead to inactivation. Nevertheless, there are enzymes which are known to be tolerant and stable in organic solvent. Most of these enzymes are secreted by bacterial strains isolated from organic-solvent-contaminated sites such as Pseudomonas sp., Bacillus sp., Rhizopus oryzae, Halobacterium sp., and Natrialba magadi. There are also reports on thermostable enzyme that is able to tolerate the presence of $25 \%(v / v)$ organic solvents and is said to have an enhanced catalytic activity [10-13]. The effect of organic solvent on enzymes may accentuate the activity of the enzyme in this situation; the organic solvent molecules interact with the enzyme at different polarities and organic solvent concentrations which improve the conformation of the enzyme. Elastase strain $\mathrm{K}$ is an organic solvent tolerant protease that is isolated from Pseudomonas aeruginosa strain K, wherein the organic solvent tolerant protease exhibits stability and enhanced activity in a wide range of polar organic solvents. In Rahman et al., recombinant elastase strain K had previously shown stability in $25 \%(v / v)$ polar organic solvents such as ethanol, methanol, 1-propanol, and DMSO [14-16]. The ability of elastase strain K to withstand a broad range of organic solvents allows it to be applied in the enzyme industry and to be run through extreme processes. Although it shows stability in organic solvents, there are still limitations regarding the wavering stability of this enzyme under other extreme conditions which outweigh the value and usefulness of the enzyme for industrial application.

To overcome pitfalls in enzyme stability, there is a technique which involves the immobilization of the enzyme. There are many techniques of enzyme immobilization that are commonly used which include adsorption, entrapment, covalent binding, and cross-linking. In general, any immobilization of an enzyme can be achieved via physical or chemical approaches. The physical approach to enzyme immobilization involves formation of linkages between enzyme molecules and the carrier, whereas when using a chemical approach, a stable linkages between enzyme molecules is achieved through the use of a cross-linking agent [17]. Both adsorption and entrapment are examples of physical immobilization, whereas covalent binding and cross-linking are examples of chemical immobilization. At the industrial level, enzyme immobilization acts to improve the mechanical stability of the enzyme, which makes the enzyme more resilient towards surfactants, chemicals, inhibitors, and reactors used. In addition, enzyme immobilization reduces contamination in the reaction medium and modifies the purity of the enzyme, which makes it increasingly selective and specific [18,19].

A cross-linked enzyme aggregate (CLEA) is a carrier-free enzyme immobilization technique whereby a cross-linking agent is used for the formation of linkages between aggregated enzyme molecules that are insoluble. The CLEA is arranged in a manner similar to a good porous support. Precipitating the free enzyme can be done by adding salts, non-ionic polymers, or water-miscible organic solvents at appropriate proportions to form aggregates. Additional bifunctional reagents such as glutaraldehyde can also form linkages through the reaction of glutaraldehyde and the active group, and in particular with the amine group of lysine residue on the surface of the enzyme. The presence of a non-catalytic carrier within the immobilized enzyme matrix further reduces the volumetric catalyst [20-22]. Eliminating the need to incorporate any solid support as a carrier maximizes the 
catalytic performance and reduces the cost of preparing the CLEA since the cross-linkers are relatively small and inexpensive [23,24].

There are some issues on CLEAs such as diffusional problems when a large substrate is used, low number of lysine residue on enzyme limits the formation of linkages with glutaraldehyde, and having a delicate nature when produced on a large scale make CLEAs more difficult to handle in industrial operation. Means to improve the preparation of CLEAs have been initiated and implemented over the years. Some of the improvements include the addition of co-aggregants such as bovine serum albumin (BSA), which acts as a protein feeder and magnetic particles for better CLEA separation $[25,26]$. While CLEAs have gained recognition over the years, studies regarding the organization and conformational structure of CLEAs remains elusive [27]. It has been hypothesized that a deep understanding of the structure of CLEAs would enable scientists to engineer CLEAs which have a maximum recovered activity.

Taking into consideration the lack of structural conformity of CLEAs, there is a need to firstly address the consequences of factors affecting aggregation and cross-linking processes of CLEAs, which include various incubation times, the concentration of glutaraldehyde as a bifunctional reagent, and the effect of co-aggregants. The optimization of these parameters has been aimed at capitalizing on the recovered activity of CLEA-elastase in order to reduce the limiting factors of CLEAs. Secondly, the biochemical and biophysical aspects of CLEA derivatives have been compared to the free enzyme. Biophysical analysis focuses on the structural organization, which comprises the primary morphology, diameter, and particle distribution in aqueous media, of CLEAs.

\section{Results}

\subsection{Effect of Glutaraldehyde Concentration on CLEA-Elastase Formation}

Glutaraldehyde is a highly reactive protein cross-linking compound acting even at very low concentrations in mixtures. Figure 1 shows the recovered activity of CLEA-elastase treated with different concentrations of glutaraldehyde. The maximum recovered activity of CLEA-elastase was recorded when $0.2 \%(v / v)$ of glutaraldehyde was used. The recovered activity of CLEA depends on the amount of linkages formed between the molecules of glutaraldehyde and the active amino group of the enzyme molecules. By applying a low concentration of glutaraldehyde, there will be an insufficient number of linkages formed, contributing to a greater loss of activity because the unimmobilized enzymes are prone to being decanted during the washing process. On the other hand, increasing the concentration of glutaraldehyde would cause the enzyme to be subjected to the formation of multipoint linkages. The excessive linkages will lead to formation of a CLEA with tiny pores, thus limiting the diffusion of a large substrate to the active site of the enzyme [21]. The highest recovered activity of CLEA-elastase was recorded at $60 \%$ based on Figure 1 . The $40 \%$ loss in enzyme activity may be attributed to the washing process or to steric hindrance.

\subsection{Effect of Glutaraldehyde Modification Time on CLEA-Elastase Formation}

Glutaraldehyde modification time is important to forming a functional CLEA with the highest recovery activity. While glutaraldehyde is known to be highly reactive, sufficient modification time is required to form enough linkages in the CLEA. Glutaraldehyde modification time showed the highest recovered activity of approximately $70 \%$ at $2 \mathrm{~h}$ according to Figure 2 . A shorter glutaraldehyde modification time would result in insufficient linkages between enzyme molecules, therefore increasing the probability of loss of the enzyme during the washing process. Conversely, a prolonged modification time would cause formation of multipoint linkages thus limiting the diffusion of the substrate into CLEAs. 


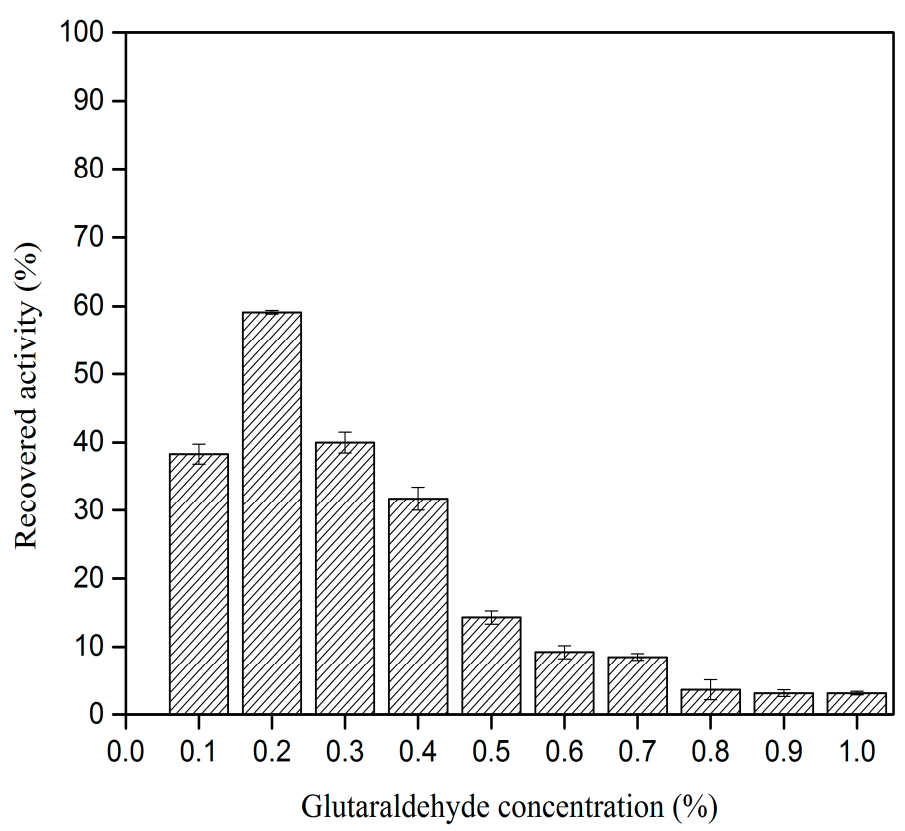

Figure 1. Effect of glutaraldehyde concentration on the recovered activity of cross-linked enzyme aggregate (CLEA)-elastase. Different concentrations of glutaraldehyde were added into aliquots of aggregated free elastase prior to incubation at $4{ }^{\circ} \mathrm{C}$ for $2 \mathrm{~h}$ with a rotating motion. The experiment was conducted in triplicate and the recovered activities are presented as mean values \pm standard error.

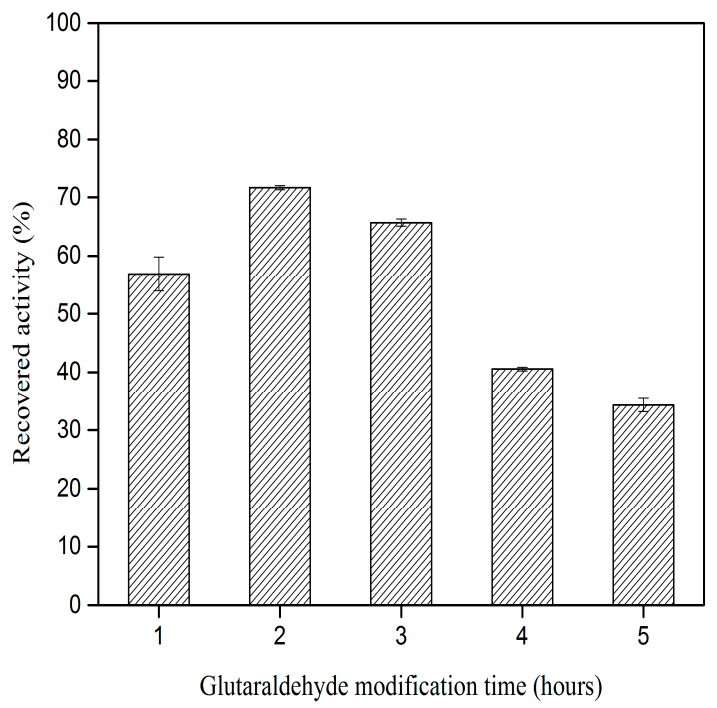

Figure 2. Effect of glutaraldehyde modification time on the recovered activity of CLEA-elastase. Glutaraldehyde with a concentration of $0.2 \%(v / v)$ was added to aliquots of aggregated free elastase prior to incubation at $4{ }^{\circ} \mathrm{C}$ with rotating motion. CLEA-elastase was collected every hour for $5 \mathrm{~h}$. The experiment was conducted in triplicate and recovered activities are presented as mean values \pm standard error.

\subsection{Effect of Different Co-Aggregants on CLEA-Elastase Formation}

Co-aggregates such as BSA and starch can be incorporated into the enzyme mixture to enhance the recovered activity of the elastase. BSA is a lysine-rich protein which acts as a spacer and protein feeder in the CLEA. This lysine-rich surface prevents excessive cross-linking between enzyme molecules, thus reducing the diffusional limitation of the substrate caused by narrow CLEA pores. Starch, on the other hand, does not provide a lysine-rich surface able to be a protein feeder, but some studies have incorporated starch into the enzyme mixture to form a porous CLEA [28,29]. CLEA formed 
separately with BSA or starch is known as CLEA-B and CLEA-S, respectively, while a mixture of BSA and starch in CLEA is identified as CLEA-SB. The incorporation of a single co-aggregant in our work enhanced the recovered activity of CLEA-elastase by $70 \%$ compared to the native CLEA, as shown in Figure 3. A maximum recovered activity of $80 \%$ was measured after both co-aggregants were mixed in the enzyme mixture. The interactions between co-aggregants regulate the extent of linkages in CLEA-elastase-SB and initiate the formation of porous CLEA which further aid the substrate diffusion. The interactions of co-aggregants with elastase contributed to the rising activity of CLEA-elastase-SB when compared to CLEA-elastase, CLEA-elastase-S, and CLEA-elastase-B [30]. Because CLEA-elastase-SB exhibited the highest recovery, among other interactions, a characterization of CLEA-elastase-SB was conducted for which the results were compared to CLEA-elastase.

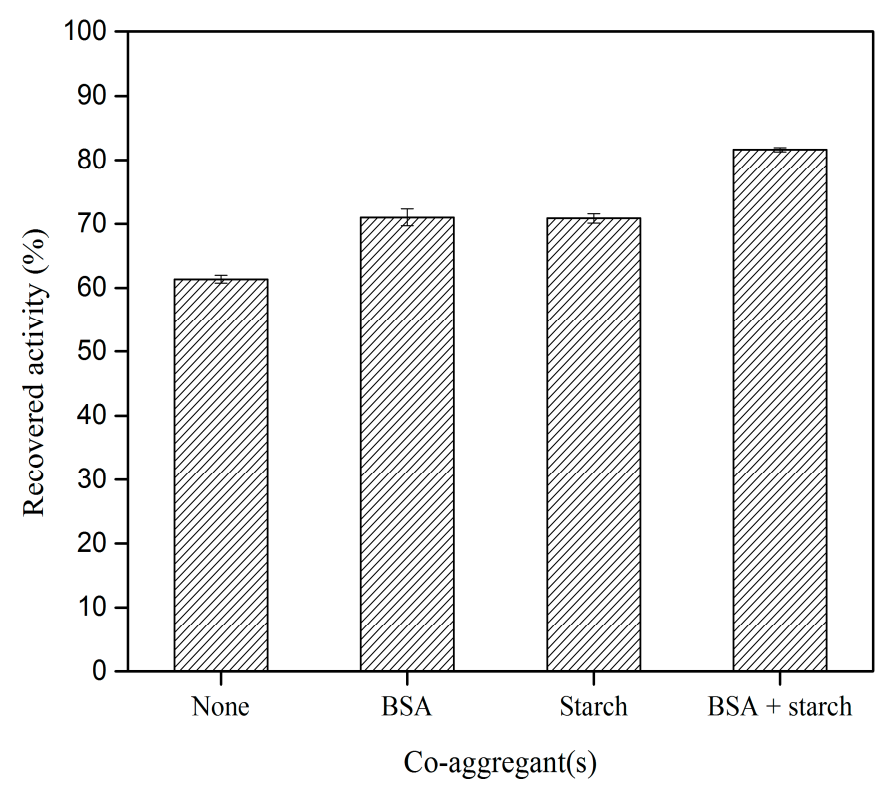

Figure 3. Effect of different co-aggregants on the recovered activity of CLEA-elastase. Ten $\mathrm{mg} / \mathrm{mL}$ of each co-aggregant was incorporated into the aggregated enzyme prior to addition of $0.2 \%(v / v)$ glutaraldehyde. The suspension underwent incubation at $4{ }^{\circ} \mathrm{C}$ for $1 \mathrm{~h}$ with rotating motion. The experiment was conducted in triplicate and recovered activities are presented as mean values \pm standard error. Legend: BSA, bovine serum albumin.

\subsection{Effect of Temperature on Proteolytic Activity of CLEA-Elastase}

The temperature profile of CLEA-elastase was compared to the free elastase. Studies by Rahman et al. have revealed that elastase strain K can be harvested from a recombinant Escherichia coli and exhibits optimum activity at $40^{\circ} \mathrm{C}$ [15]. CLEA-elastase derivatives, on the other hand, exhibit an optimum temperature at $50{ }^{\circ} \mathrm{C}$, as shown in Figure $4 \mathrm{a}$. The thermal stability of CLEA-elastase was measured by pre-incubating the samples at different temperatures for $30 \mathrm{~min}$ before subjecting them to a proteolytic assay at the optimal temperature. The thermal stability profile as shown in Figure $4 \mathrm{~b}$ reveals that the CLEA-elastase derivatives exhibit better tolerance and activity at higher temperature. The improvement of elastase activity can be observed at $50^{\circ} \mathrm{C}$ for both CLEA-elastase and CLEA-elastase-SB. The immobilized elastase for CLEA-elastase and CLEA-elastase-SB at $60{ }^{\circ} \mathrm{C}$ achieved a relatively high recovered activity, being $67.7 \%$ and $84.6 \%$, respectively. By contrast, free elastase exhibited a decline in protease activity at the said temperature. The presence of linkages between enzyme molecules in CLEA-elastase provides an additional stability and rigidity to CLEA-elastase which causes the interaction to be more resilient to high temperature. Nonetheless, at $70^{\circ} \mathrm{C}$, all samples exhibited a loss in activity as a result of the rupturing of the bonds within the enzyme, with the bonds that were ruptured having been essential in maintaining the catalytic conformation of the enzyme [31,32]. 


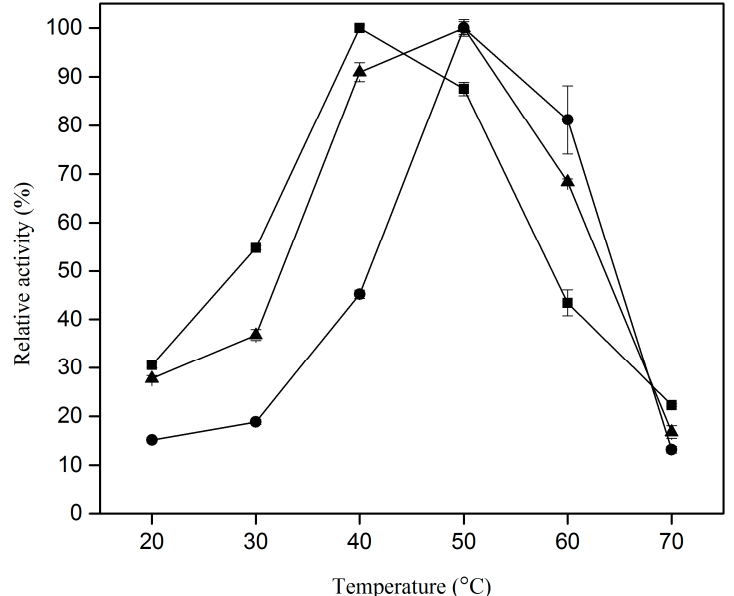

(a)

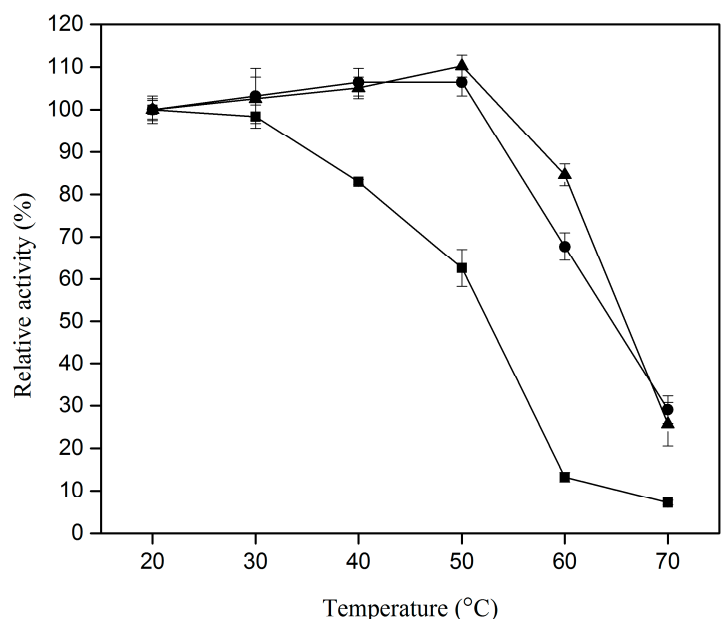

(b)

Figure 4. Temperature profile of elastase and its CLEA derivatives. (a) The effect of temperature on the optimum temperature of CLEA-elastase (๑) and CLEA-elastase formed with starch and BSA $($ CLEA-elastase-SB) $(\mathbf{\Lambda})$ in comparison with free elastase $(\mathbf{\square})$; (b) thermal stability of CLEA-elastase ( and CLEA-elastase-SB ( $\mathbf{\Lambda})$ in comparison with free elastase ( $\boldsymbol{(})$. The experiment was conducted in triplicate and relative activities are presented as mean values \pm standard error.

\subsection{Effect of $\mathrm{pH}$ on Proteolytic Activity of CLEA-Elastase}

The effect of $\mathrm{pH}$ on proteolytic activity of CLEA-elastase was studied. Samples containing the enzyme were subjected to pre-incubation in $50 \mathrm{mM}$ of various buffer systems with $\mathrm{pH}$ ranging from 4 to 11. In furtherance to the assays at different $\mathrm{pH}$ levels, both free elastase and CLEA-elastase were shown to have the highest activity at $\mathrm{pH} 8$ as shown in Figure 5, whereas the CLEA-elastase-SB showed a relatively high activity at $\mathrm{pH} 8, \mathrm{pH} 9$, and $\mathrm{pH} 10$, having a relative activity of $100 \%, 96 \%$ and $80 \%$ at these $\mathrm{pH}$ levels, respectively. Changes in $\mathrm{pH}$ can alter the ionic charge of the protein residue, which corresponds to conformational changes in the catalytic region. Under a high $\mathrm{pH}$, protein residues were deprotonated and the ionic charges reduced the relative activity of CLEA-elastase and CLEA-elastase-SB. A lower relative activity was found at the acidic point where the surroundings had a $\mathrm{pH}$ that was close to the isoelectric point of the substrate, which affects the activity of the enzyme [31].

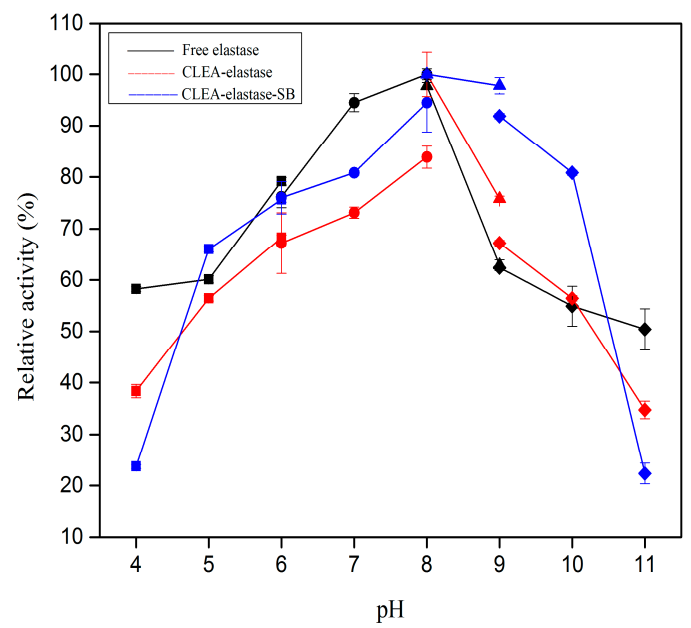

Figure 5. $\mathrm{pH}$ profile of elastase and its CLEA derivatives. For each $\mathrm{pH}$ range, $50 \mathrm{mM}$ of different buffer systems was used, namely, sodium acetate $(\boldsymbol{\bullet})$, potassium phosphate $(\boldsymbol{\bullet})$, Tris- $\mathrm{Cl},(\boldsymbol{\Lambda})$ and glycine- $\mathrm{OH}(\diamond)$. The experiment was conducted in triplicate and relative activities are presented as mean values \pm standard error. 


\section{6. $p H$ Stability of CLEA-Elastase}

Elastase strain $\mathrm{K}$ has a wide $\mathrm{pH}$ stability profile. The free elastase was found to retain proteolytic activity of up to $80 \%$ between $\mathrm{pH} 5$ to $\mathrm{pH} 10$ as shown in Figure 6. CLEA-elastase derivatives, on the other hand, retained up to $60 \%$ enzyme activity at $\mathrm{pH} 4$, which increased the enzyme stability threefold compared to free elastase at a similar $\mathrm{pH}$. Apart from this, the enzyme activities of CLEA-elastase and CLEA-elastase-SB were also preserved by up to $90 \%$ between $\mathrm{pH} 5$ to $\mathrm{pH} 9$. While the $\mathrm{pH}$ stability profile of CLEA-elastase and free elastase were homologous at $\mathrm{pH} 10$ and $\mathrm{pH}$ 11, CLEA-elastase-SB showed stability at a similar range of $\mathrm{pH}$ with relative activities of $92 \%$ and $81 \%$, respectively.

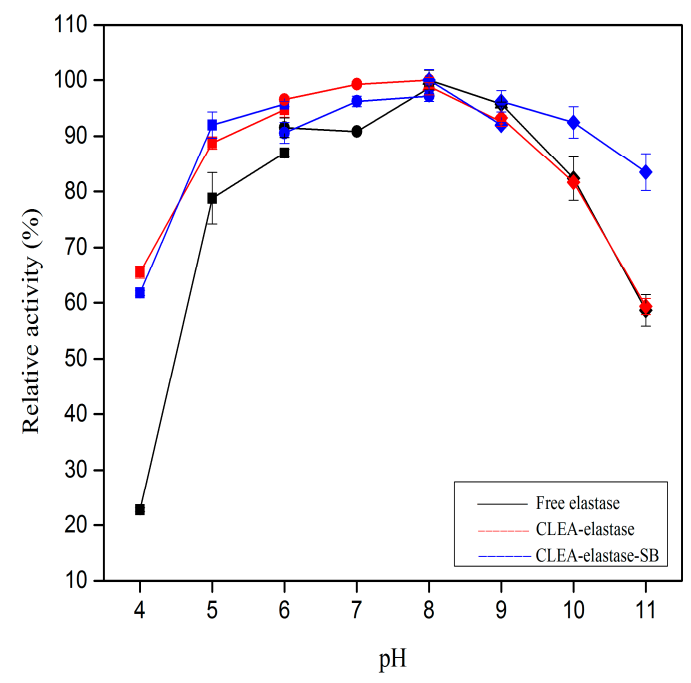

Figure 6. The $\mathrm{pH}$ stability profile of free elastase and CLEA-elastase derivatives. For every $\mathrm{pH}$ a different buffer system with a concentration of $50 \mathrm{mM}$ was provided, and the buffer systems comprised sodium acetate $(\boldsymbol{\bullet})$, potassium phosphate $(\bullet)$, Tris- $\mathrm{Cl}(\boldsymbol{\bullet})$, and glycine-OH $(\bullet)$. The experiment was conducted in triplicate and relative activities are presented as mean values \pm standard error.

\subsection{Stability of CLEA-Elastase in Organic Solvents}

Elastase strain $\mathrm{K}$ is a known organic solvent tolerant enzyme for which, according to Table 1, the activity of the enzyme was preserved by up to $75 \%$ in polar and non-polar organic solvents. A significantly higher enzyme activity of CLEA-elastase in organic solvents indicates that the stability of the enzyme has changed in lieu of the formation of CLEA compared to free enzymes. Improvements in enzyme activity could be observed when CLEA-elastase was treated with organic solvents which had $\log \mathrm{P}_{\mathrm{o} / \mathrm{w}}$ values of -0.33 to 3.15. In particular, the presence of organic solvents such as acetonitrile, ethanol, benzene, and xylene was found to be the reason for which the activity became higher than that of the control, as shown by significantly high activities of $164 \%, 172 \%, 152 \%$, and $133 \%$, respectively. The improvements of CLEA-elastase activity could also be observed in 1-propanol. Compared to free elastase, which became detrimental after being treated with 25\% $(v / v) 1$-propanol, CLEA-elastase was able squeeze off the effects by retaining an enzyme activity which was $11 \%$ higher than that of the control. With the exception of $25 \%(v / v)$ toluene, CLEA-elastase was able to maintain a relatively high enzyme activity within the rest of the organic solvents studied. The organic solvent treatment of CLEA-elastase-SB revealed that all samples retained their proteolytic activity except for DMSO. In $25 \%(v / v)$ DMSO, the relative activity of CLEA-elastase-SB plunged to $48 \%$ compared to the activity of the control. The massive decline in protease activity in DMSO was due to the fact that the polarity of DMSO took a toll on the co-aggregants, which further disrupted the overall stability of the CLEA. Although CLEA immobilization seeks to improve the stability of the enzyme, organic solvent has been shown to be the main factor that could pose a detrimental effect to the co-aggregants. This effect will prevent the co-aggregants from effectively enhancing the enzymatic performance of CLEA-elastase. 
Table 1. Stability of free elastase and CLEA-elastase derivatives in $25 \%(v / v)$ organic solvents for $30 \mathrm{~min}$ represented using relative activity (\%). Enzyme activity without organic solvent treatment was taken to be $100 \%$. The experiment was conducted in triplicate and recovered activities are presented as mean values \pm standard error.

\begin{tabular}{ccccc}
\hline Organic Solvents & $\log \boldsymbol{P}_{\boldsymbol{o} / \boldsymbol{w}}$ & Free Elastase & CLEA-Elastase & CLEA-Elastase-SB \\
\hline Control & - & 100 & 100 & 100 \\
DMSO & -1.30 & $102.39 \pm 1.64$ & $104.55 \pm 3.20$ & $47.59 \pm 2.06$ \\
Methanol & -0.78 & $87.29 \pm 1.06$ & $111.36 \pm 3.18$ & $101.87 \pm 1.64$ \\
Acetonitrile & -0.33 & $82.81 \pm 0.71$ & $164.55 \pm 1.15$ & $100.80 \pm 1.13$ \\
Ethanol & -0.24 & $79.22 \pm 1.91$ & $172.73 \pm 3.57$ & $101.34 \pm 0.87$ \\
1-propanol & 0.28 & $31.39 \pm 1.21$ & $111.36 \pm 2.16$ & $94.12 \pm 5.81$ \\
Benzene & 2.13 & $79.52 \pm 1.74$ & $152.73 \pm 1.22$ & $98.40 \pm 4.57$ \\
Toluene & 2.50 & $86.70 \pm 0.77$ & $96.36 \pm 2.87$ & $79.14 \pm 0.34$ \\
Xylene & 3.15 & $82.96 \pm 0.62$ & $133.18 \pm 0.84$ & $89.84 \pm 0.59$ \\
\hline
\end{tabular}

\subsection{Reusability of CLEA-Elastase}

The benefits of immobilization via the CLEA method stand with the easy separation of the enzyme from the reaction medium where the cross-linking of the enzyme would render them insoluble. The reusability of CLEA-elastase was evaluated for up to 10 cycles with the first cycle being $100 \%$. After the first cycle, the recovered activity of CLEA-elastase and CLEA-elastase-SB declined to 89\% and $97 \%$, respectively, as shown in Figure 7. In general, the presence of co-aggregants in the CLEA showed an improvement in recovery activity per cycle. The presence of BSA acts as a spacer and protein feeder which controls the degree of linkage and stabilizes the enzyme structure. The optimization parameter of glutaraldehyde used and the co-aggregants aided in the formation of a CLEA with an adequate rigidity to withstand numerous cycles and an adequate pore size for effective substrate diffusion [27]. The recovered activity of CLEA-elastase was found to be $50 \%$ when reaching the ninth cycle while CLEA-elastase-SB had a recovered activity of $61 \%$ at the tenth cycle.

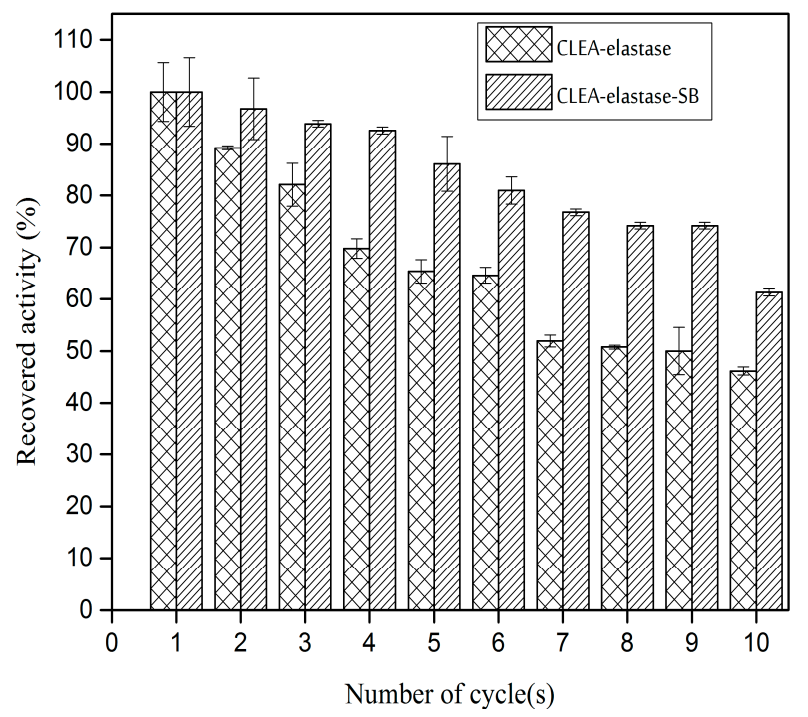

Figure 7. Reusability of CLEA-elastase and CLEA-elastase-SB. The experiment was conducted in triplicate and recovered activities are presented as mean values \pm standard error.

\subsection{Scanning Electron Microscopy of CLEA-Elastase}

SEM analysis was conducted on dried samples of CLEA-elastase and CLEA-elastase-SB with the exception of the free elastase due to its solubility. The structure of the CLEA under an electron microscope could be classified into two types depending on the conformation of aggregates. The type 
1 aggregate formed a ball-like structure while the type 2 aggregate formed a less defined and more random aggregation [27]. SEM images of CLEA-elastase and CLEA-elastase-SB revealed that the CLEAs majorly exhibited a type 2 aggregate. Although the type 2 aggregate was more random in its overall structure, there was a uniformity in the size of the molecules that made up the structure of the CLEA, as shown in Figure 8. While both CLEAs exhibited a type 2 aggregate structure, CLEA-elastase-SB was different in that the molecules that made up the aggregates were more robust since the co-aggregant present acted as a spacer and protein feeder to the enzyme molecules. The co-aggregants increased the surface area of the CLEA, allowing for more substrate binding and enhancing the enzyme activity.

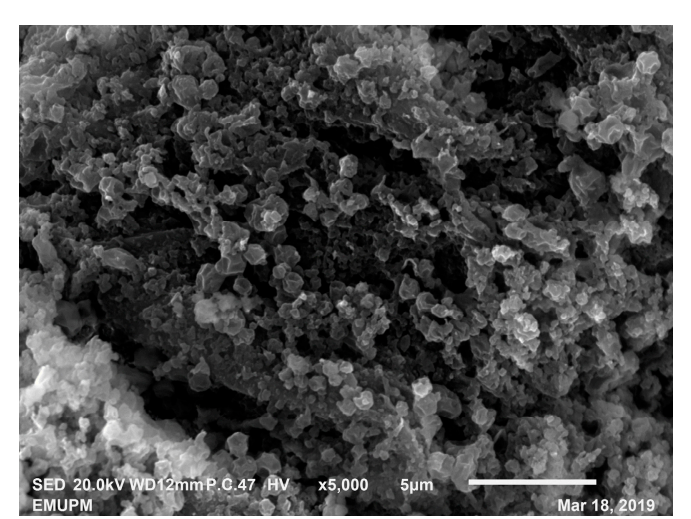

(a)

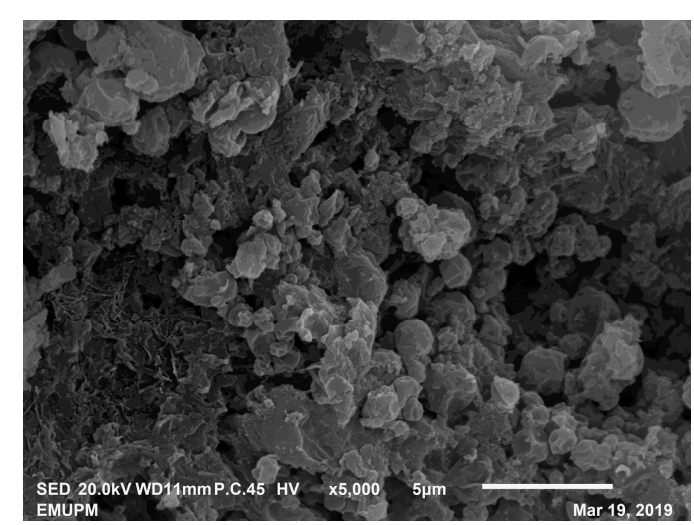

(b)

Figure 8. SEM images of CLEA-elastase (a) and CLEA-elastase-SB (b). Both images were taken under $5000 \times$ magnification.

\subsection{Dynamic Light Scattering (DLS) of CLEA-Elastase}

The particle sizes of free elastase strain K and CLEA-elastase were determined using DLS analysis. Based on Figure 9, the data from DLS revealed that free elastase, CLEA-elastase, and CLEA-elastase-SB showed diameters of $330 \mathrm{~nm}, 1109 \mathrm{~nm}$, and $1497 \mathrm{~nm}$, respectively. A major difference between free and immobilized elastase was attributed to the cross-linking of large aggregates in CLEA-elastase and CLEA-elastase-SB. The difference in the diameter of CLEA-elastase and CLEA-elastase-SB was coherent with the SEM images of both samples, in which CLEA-elastase-SB appeared morphologically larger and robust in size when compared to CLEA-elastase. The DLS analysis of CLEA-elastase also exhibited a small peak which may be attributed to the detection of a small aggregate present in the mixture. The small aggregate in CLEA-elastase occurred due to mechanical stress during physical separation. Hence, this finding supports reports on the delicate nature of native CLEAs $[19,33]$. 


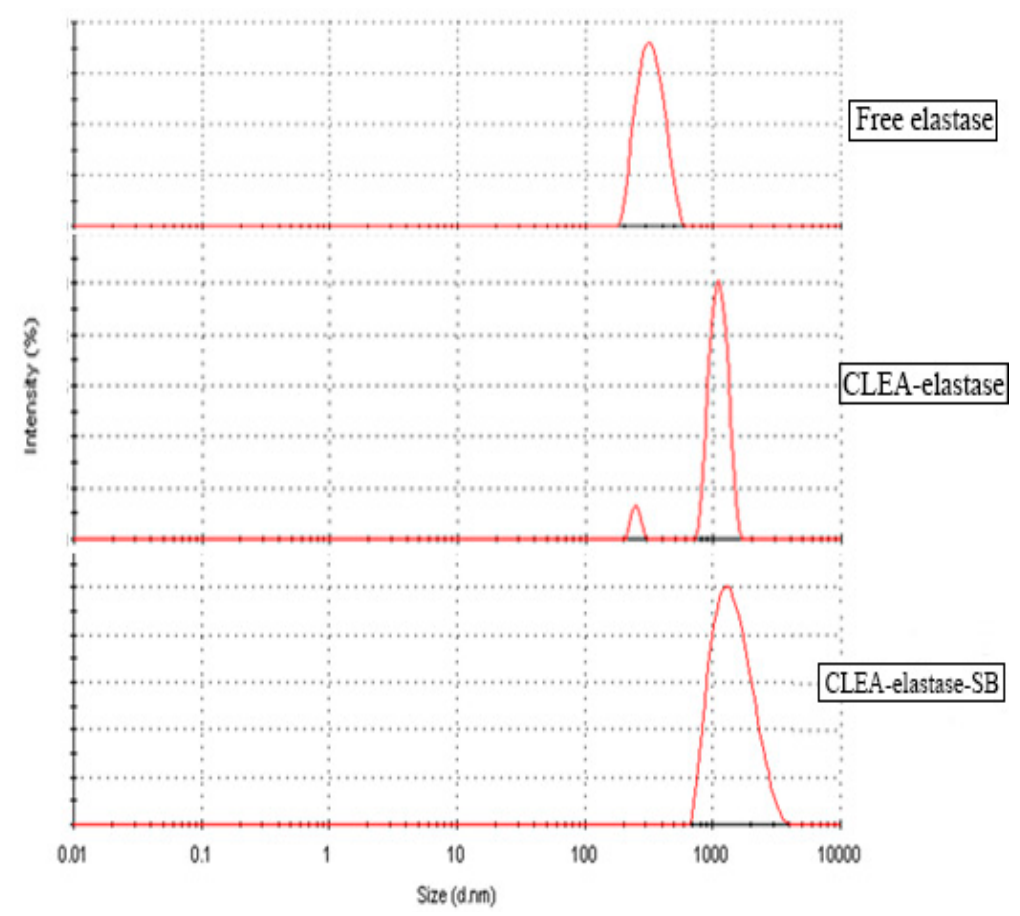

Figure 9. Dynamic light scattering (DLS) analysis of free elastase, CLEA-elastase, and CLEA-elastase-SB.

\section{Discussion}

Organic solvent tolerant enzymes are valuable biocatalysts for industry. Despite their importance, only a few studies have been found to conduct immobilization on the enzymes and one of these used the organic solvent tolerant protease [34-36]. This study attempted to immobilize an organic solvent tolerant elastase strain $\mathrm{K}$ using the CLEA method and to determine whether this type of immobilization would affect the organic solvent tolerant property of this enzyme. Following the preservation of the organic solvent tolerant property of CLEA-elastase, the biophysical and biochemical properties of CLEA-elastase were studied.

Glutaraldehyde is used as the protein cross-linking reagent. The chemical reacts actively with the amino group of the enzyme forming a CLEA as a result of a Schiff base reaction. In fact, there are many proposed mechanisms of reactions of glutaraldehyde since the reaction in aqueous environment might be affected by the $\mathrm{pH}$ of solution, the presence of active amino groups, and the ability to form many conjugates. The reactive groups in glutaraldehyde are in equilibrium between its polymeric and monomeric configuration. Reactions under acidic or neutral conditions may involve the formation of a Schiff base and nucleophilic attack on the amino group of the protein. On the other hand, the reaction of glutaraldehyde under alkaline conditions has been found to undergo two mechanisms: the formation of a Schiff base and the Michael addition of $C-C$ bonds forming the linkages [21,37]. The linkages formed by the reaction of glutaraldehyde and the amino group of the enzyme have been said to have good stability against high temperature and a wide range of $\mathrm{pH}$ values [30,31]. As glutaraldehyde is highly reactive, the formation of linkages in a CLEA could be achieved by using a small amount of glutaraldehyde and incubation for a short treatment time. An insufficient incubation time and amount of glutaraldehyde might lead to a low degree of cross-linking and increase the possibility of enzyme leaching while an excessive incubation time and amount of glutaraldehyde will cause steric hindrance and low substrate diffusion [38]. Nonetheless, enzymes immobilized using the CLEA method experience loss of activity which can be attributed to enzyme leaching. Leaching produces smaller CLEA aggregates which have a tendency to be lost during the washing process. Hence, incorporation of co-aggregants in the enzyme mixture could provide a support for the aggregates to link onto and form a more rigid CLEA structure. Following this, CLEA-elastase has been found 
to exhibit an enhanced stability under high temperature when compared to free elastase, which is coherent with subsequent CLEA studies [39-41]. The enhanced tolerance of CLEA-elastase towards high temperature is a result of increased rigidity of the structure caused by additional linkage between enzyme molecules. More energy is needed to weaken the durable linkage of the CLEA that prolongs CLEA-elastase stability at high temperature. A shift in the optimum temperature by $10^{\circ} \mathrm{C}$ has been found to be a result of increased rigidity of the CLEA structure because in this case more energy was used to bring about the optimum functional conformational state of CLEA-elastase to catalyze a reaction [42]. The optimal $\mathrm{pH}$ profile of CLEA-elastase and free elastase have not displayed a significant change. In one study, a regular shift in obtaining the optimal $\mathrm{pH}$ under a slight alkaline condition was observed, and there have also been cases where CLEA immobilization did not shift the optimum $\mathrm{pH}$ of the enzyme [43]. Regardless of the shifting of the optimum $\mathrm{pH}$, it is clear that CLEAs improve the $\mathrm{pH}$ stability of the enzyme. The $\mathrm{pH}$ stability profile covers a wide $\mathrm{pH}$ range, suggesting that CLEAs contribute to enzyme stabilization against protonation and deprotonation.

Elastase strain $\mathrm{K}$ has been shown to possess stability in organic solvents. Immobilization of elastase strain $\mathrm{K}$ has been linked to enhancing the operational and storage stability of the enzyme and preserving or enhancing the organic solvent tolerant characteristic. In industry, organic solvents are often used to minimize the reverse reaction and to shift the reaction towards completion of synthesis. However, organic solvents are usually toxic to the enzyme and cause denaturation. The stability of CLEA-elastase in organic solvent is enhanced and yields better activity in organic solvents with low $\log P_{\mathrm{o} / \mathrm{w}}$. Even in its free form, elastase strain $\mathrm{K}$ has been found to exhibit better stability in polar solvents due to the presence of a disulfide-bridge and the reaction of its aspartate residue with water molecules in the organic solvent [44]. Formation of linkages in CLEA-elastase holds the structural conformation of the enzyme which leads to the enhancement of enzyme activity in non-polar organic solvents. CLEA-elastase-SB has been found to exhibit lower yields compared to CLEA-elastase due to the effect of organic solvents on the co-aggregants. CLEA-elastase-SB appears to be more stable in terms of reusability compared to CLEA-elastase. The loss of enzyme activity after each cycle has been linked to the leaching of the enzyme or mechanical stress during centrifugation causing the CLEA pellet to clump [36]. Our SEM images showed that CLEA-elastase exhibits a type 2 aggregate and this coheres with studies suggesting that type 2 aggregates are often formed by hydrophilic enzymes [45]. The DLS analysis provided insight into the diameter size of the aggregate in aqueous media, where the diameter of CLEA-elastase appeared to be significantly larger than that of a free elastase.

\section{Materials and Methods}

\subsection{Bacterial and Enzyme Source}

Recombinant E. coli KRX/pCon2(3) harboring the organic solvent tolerant elastase strain $\mathrm{K}$ gene was obtained from the Enzyme and Microbial Technology (EMTech) Research Centre, Faculty of Biotechnology and Biomolecular Sciences, Universiti Putra Malaysia. Overexpression of elastase strain $\mathrm{K}$ was conducted according to Rahman et al. [11]. The bacterial culture was then sonicated thrice with $30 \%$ duty cycle and 8 control output settings to harvest the enzyme.

\subsection{Assay of Proteolytic Activity}

Proteolytic activity of elastase strain $\mathrm{K}$ was measured using the azocasein method. The azocasein method was conducted based on Rahman et al. with slight modification [16]. Azocasein $(0.5 \%(w / v))$ was first dissolved in $0.1 \mathrm{M}$ tris-Cl buffer at $\mathrm{pH}$ 7. One hundred microliters of enzyme sample was added into $1 \mathrm{~mL}$ of the azocasein substrate and incubated in a water bath shaker for $30 \mathrm{~min}$ at $37^{\circ} \mathrm{C}$ and $150 \mathrm{rpm}$. The reaction was terminated by adding an equal amount of $10 \%(w / v)$ trichloroacetic acid (TCA). The mixture was further incubated at room temperature for another $30 \mathrm{~min}$ and was centrifuged at $13,000 \times g$ for $10 \mathrm{~min}$ afterwards. One hundred microliters of the supernatant was pipetted into a 96-well microplate and an equal amount of $1 \mathrm{M} \mathrm{NaOH}$ was added to yield a yellowish orange color. 
The absorbance was read at $450 \mathrm{~nm}$ using a microplate reader. A blank sample was prepared by replacing the enzyme sample with buffer under the same procedure.

\subsection{Preparation of CLEA-Elastase}

Preparation of CLEA involved two processes: aggregation of the enzyme and glutaraldehyde modification time. For enzyme aggregation, $60 \%(w / v)$ of ammonium sulfate was slowly added into crude elastase strain $\mathrm{K}$. Once the ammonium sulfate was completely dissolved, the enzyme suspension was incubated at $4{ }^{\circ} \mathrm{C}$ with gentle stirring for $3 \mathrm{~h}$. For the glutaraldehyde modification time, $0.2 \%$ $(v / v)$ glutaraldehyde was added into the suspension and incubated for $2 \mathrm{~h}$ at $4{ }^{\circ} \mathrm{C}$ with gentle stirring. The enzyme suspension was then centrifuged at $13,000 \times g$ for $10 \mathrm{~min}$. The CLEA-elastase pellet was washed with $50 \mathrm{mM}$ tris- $\mathrm{Cl}$ buffer at $\mathrm{pH} 7$ thrice to remove excess glutaraldehyde.

CLEA-elastase-SB was prepared by adding $10 \mathrm{mg} / \mathrm{mL}$ BSA and starch into the enzyme suspension prior to adding glutaraldehyde. The mixture was then incubated for $2 \mathrm{~h}$ at $4{ }^{\circ} \mathrm{C}$ with gentle stirring for the cross-linking process. The CLEA formed was then centrifuged at $13,000 \times g$ for $10 \mathrm{~min}$ and the pellet washed a few times to remove residual glutaraldehyde and co-aggregants. The recovered activity of CLEA-elastase was then calculated using Formula (1).

$$
\text { Recovered activity }(\%)=\frac{\text { Proteolytic activity of free enzyme }}{\text { Proteolytic activity of CLEA }} \times 100 \%
$$

\subsection{Optimum Temperature and Thermal Stability of CLEA-Elastase}

The effects of temperature on free elastase and CLEA-elastase were determined from $20^{\circ} \mathrm{C}$ to $70{ }^{\circ} \mathrm{C}$ using $10{ }^{\circ} \mathrm{C}$ increments. For determination of the optimum temperature, a mixture of the enzyme sample and the azocasein substrate were incubated at different temperatures for $30 \mathrm{~min}$ before the absorbance was taken to determine the enzyme activity. The highest enzyme activity for each sample was considered to be $100 \%$ and served as the control. The thermal stability of free elastase and CLEA-elastase were determined by pre-incubating the enzyme samples at different temperatures for $30 \mathrm{~min}$ prior to addition of the azocasein substrate and were assayed at the optimum temperature. Enzyme activity at $20{ }^{\circ} \mathrm{C}$ was considered to be $100 \%$ and served as the control.

\subsection{Optimum $\mathrm{pH}$ and $\mathrm{pH}$ Stability of CLEA-Elastase}

The effects of $\mathrm{pH}$ on free elastase and CLEA-elastase were determined using $50 \mathrm{mM}$ different buffer systems, i.e., sodium acetate ( $\mathrm{pH} 4-6$ ), potassium phosphate ( $\mathrm{pH}$ 6-8), Tris- $\mathrm{Cl}(\mathrm{pH} 8-9)$, and glycine-OH ( $\mathrm{pH}$ 9-11). Different buffer systems were used as each system has their own $\mathrm{pH}$ range. Determination of optimum $\mathrm{pH}$ was conducted by dissolving the azocasein substrate in the respective buffer system prior to addition of enzyme samples for the assay analysis. Determination of $\mathrm{pH}$ stability was conducted by re-suspending and pre-incubating the enzyme samples in different $\mathrm{pH}$ for $30 \mathrm{~min}$ at room temperature before proteolytic assays were undergone at the optimum temperature. The proteolytic assay in both tests was conducted at the optimum temperature measured earlier.

\subsection{Stability of CLEA-Elastase in Organic Solvent}

Organic solvent stability of free elastase and CLEA-elastase was determined by pre-incubating the enzyme samples with $25 \%(v / v)$ of different organic solvents at room temperature for $30 \mathrm{~min}$. The samples were then assayed using azocasein at the optimum temperature measured earlier for another $30 \mathrm{~min}$. Enzyme samples without organic solvent treatment were considered to be $100 \%$ and serve as the control. The selection of organic solvents was based on their boiling point not exceeding the optimum temperature used in the assay. 


\subsection{Reusability of CLEA-Elastase}

The soluble free elastase could not be reused and thus reusability tests were conducted on the CLEA-elastase derivatives. The reusability test for CLEA-elastase and CLEA-elastase-SB was determined by assaying the enzyme samples for up to 10 cycles. The proteolytic assay was conducted using the azocasein substrate and incubated at the optimum temperature measured earlier. After a cycle of the proteolytic assay, the insoluble immobilized enzyme was separated from the reaction medium by centrifugation at $13,000 \times g$ for $10 \mathrm{~min}$. A pellet of CLEA-elastase was washed and re-suspended in $50 \mathrm{mM}$ Tris-Cl buffer to remove any residual azocasein substrate. Enzyme activity of the first cycle was considered to be $100 \%$ and served as the control.

\subsection{Structural Analysis of CLEA-Elastase}

Structural analysis and particle size distribution of the free elastase and CLEA-elastase derivatives were determined using JSM-IT100 In TouchScope scanning electron microscope (SEM) and Malvern ZetaSizer (UK) dynamic light scattering (DLS) respectively.

\section{Conclusions}

The data presented in this work have revealed that the organic solvent tolerant elastase strain $\mathrm{K}$ is able to be successfully immobilized using the CLEA method. While immobilization using the CLEA method has often been reported as causing a significant loss of enzyme activity, CLEA-elastase has been shown to retain up to $70 \%$ the enzyme activity. The recovered activity of CLEA-elastase was improved after a series of optimization measures of aggregation and cross-linking parameters including saturation of the precipitant, amount of glutaraldehyde, incubation time, and the effects of co-aggregants. Immobilization of elastase strain $\mathrm{K}$ using a CLEA also did not have any detrimental effects on the existing organic solvent tolerant characteristic of the enzyme. In fact, the presence of additional linkages in CLEAs has been shown to further enhance its tolerance and stability in a wide range of organic solvents. Despite the fact that a structural analysis of CLEAs still remains elusive, SEM and DLS analyses of CLEA-elastase revealed that the morphology and diameter of the aggregates were significantly larger compared to those measured with free elastase. The structural analysis of CLEAs is continuously becoming an interesting subject to consider.

Author Contributions: Conceptualization, M.S.M.R. and M.S.M.A.; data curation, M.S.M.R.; formal analysis, M.S.M.R. and M.S.M.A.; funding acquisition, M.S.M.A.; methodology, M.S.M.R. and M.S.M.A.; project administration, M.S.M.A.; resources, R.N.Z.R.A.R.; supervision, M.S.M.A.; writing—original draft preparation, M.S.M.R.; writing-review and editing, M.S.M.A., F.M.S., and R.N.Z.R.A.R. All authors have read and agreed to the published version of the manuscript.

Funding: This research was funded by High Performance Individual Research Grants (grant number 9521700) and M.S.M.R was funded by a Graduate Research Fellowship (GRF) from Universiti Putra Malaysia.

Acknowledgments: The author thank Norhayati Yaacob for proofreading the article and Institute of Bioscience (IBS), Universiti Putra Malaysia (UPM) for SEM analysis.

Conflicts of Interest: The authors declare no conflict of interest.

\section{References}

1. Sheldon, R.A. Cross-Linked Enzyme Aggregates as Industrial Biocatalysts. Org. Process Res. Dev. 2011, 15, 213-223. [CrossRef]

2. Walsh, G. Industrial Enzymes: Proteases and Carbohydrases. Proteins Biochem. Biotechnol. 2015, 327-369. [CrossRef] 
3. Li, Q.; Yi, L.; Iverson, B.L. Commercial proteases: Present and future. FEBS Lett. 2013, 587, 1155-1163. [CrossRef] [PubMed]

4. Sawant, R.; Nagendran, S. Protease: An enzyme with multiple industrial applications. World J. Pharm. Pharm. Sci. 2014, 3, 568-579.

5. Ahmad, R.; Sardar, M. Enzyme Immobilization: An Overview on Nanoparticles as Immobilization Matrix. Biochem. Anal. Biochem. 2015, 4, 1.

6. Jesionowski, T.; Zdarta, J. Enzyme immobilization by adsorption: A review. Adsorption 2014, 20, 801-821. [CrossRef]

7. Laane, C.; Boeren, S.; Vos, K.; Veeger, C. Rules for Optimization of Biocatalysis in Organic Solvents. Biotechnol. Bioeng. 2009, 102, 1-8. [CrossRef]

8. Ivanov, I.P.; Kasche, V.; Petkov, D.D. Thermodynamics of Enzymic Peptide Synthesis in Biphasic Aqueous-Organic Systems: Coupling of the Chemical and Phase Equilibria. Biocatal. Biotransform. 1996, 14, 181-194. [CrossRef]

9. Kasche, V.; Michaelis, G.; Galunsky, B. Binding of Organic Solvent Molecules Influences the $\mathrm{P}_{1}{ }^{\prime}-\mathrm{P}_{2}{ }^{\prime}$ Stereo-and Sequence-Specificity of $\alpha$-Chymotrypsin in Kinetically Controlled Peptide Synthesis. Biotechnol. Lett. 1991, 13, 75-80. [CrossRef]

10. Doukyu, N.; Ogino, H. Organic solvent-tolerant enzymes. Biochem. Eng. J. 2010, 48, 270-282. [CrossRef]

11. Gu, Z.; Lai, J.; Hang, J.; Zhang, C.; Wang, S.; Jiao, Y.; Liu, S.; Fang, Y. Theoretical and experimental studies on the conformational changes of organic solvent-tolerant protease from Bacillus sphaericus DS11 in methanol/water mixture. Int. J. Biol. Macromol. 2019, 128, 603-609. [CrossRef] [PubMed]

12. Qureshi, A.S.; Simair, A.A.; Ali, C.H.; Khushk, I.; Khokhar, J.A.; Ahmad, A.; Danish, M.; Lu, C. Production, Purification and Partial Characterization of Organo-Solvent Tolerant Protease from Newly Isolated Bacillus sp. BBXS-2. Ferment. Technol. 2018, 7, 2. [CrossRef]

13. Ogino, H.; Yasui, K.; Shiotani, T.; Ishihara, T.; Ishikawa, H. Organic Solvent-Tolerant Bacterium Which Secretes an Organic Solvent-Stable Proteolytic Enzyme. Appl. Environ. Microbiol. 1995, 61, 4258-4262. [PubMed]

14. Rahman, R.N.Z.A.; Geok, L.P.; Basri, M.; Salleh, A.B. Physical factors affecting the production of organic solvent-tolerant protease by Pseudomonas aeruginosa strain K. Bioresour. Technol. 2005, 96, 429-436. [CrossRef] [PubMed]

15. Rahman, R.N.Z.A.; Geok, L.P.; Basri, M.; Salleh, A.B. An organic solvent-stable alkaline protease from Pseudomonas aeruginosa strain K: Enzyme purification and characterization. Enzyme Microb. Technol. 2006, 39, 1484-1491. [CrossRef]

16. Rahman, R.N.Z.A.; Salleh, A.B.; Basri, M.; Wong, C.F. Role of $\alpha-$ Helical Structure of Organic Solvent-Activated Homodimer of Elastase Strain, K. Int. J. Mol. Sci. 2011, 12, 5797-5814. [CrossRef] [PubMed]

17. Zdarta, J.; Meyer, A.S.; Jesionowski, T.; Pinelo, M. A General Overview of Support Materials for Enzyme Immobilization: Characteristics, Properties, Practical Utility. Catalysts 2018, 8, 92. [CrossRef]

18. Rodrigues, R.C.; Ortiz, C.; Berenguer-Murcia, A.; Torres, R.; Fernandez-Lafuente, R. Modifying enzyme activity and selectivity by immobilization. Chem. Soc. Rev. 2013, 42, 6290. [CrossRef]

19. Garcia-Galan, C.; Berenguer-Murcia, A.; Fernandez-Lafuente, R.; Rodrigues, R.C. Potential of Diferent Enzyme Immobilization Strategies to Improve Enzyme Performance. Adv. Synth. Catal. 2011, 353, 2885-2904. [CrossRef]

20. Sheldon, R.A. Cross-linked enzyme aggregates $\left(\mathrm{CLEA}^{\circledR} \mathrm{S}\right)$ : Stable and recyclable biocatalysts. Biochem. Soc. Trans. 2007, 35, 1583-1587. [CrossRef]

21. Barbosa, O.; Ortiz, C.; Berenguer-Murcia, A.; Torres, R.; Rodrigues, R.C.; Fernandez-Lafuente, R. Glutaraldehyde in bio-catalysts design: A useful crosslinker and a versatile tool in enzyme immobilization. RSC Adv. 2014, 4, 1583. [CrossRef]

22. Sheldon, R.A.; Schoevaart, R.; Van Langen, L.M. Cross-linked enzyme aggragates (CLEAs): A novel and versatile method for enzyme immobilization (a review). Biocatal. Biotransform. 2005, 23, 141-147. [CrossRef]

23. Rojas, M.J.; Amaral-Fonseca, M.; Zanin, G.M.; Fernandez-Lafuente, R.; Giordano, R.D.L.C.; Tardioli, P.W. Preparation of Crosslinked Enzyme Aggregates of a Thermostable Cyclodextrin Glucosyltransferase from Thermoanaerobacter sp. Critical Effect of the Cross-linking Agent. Catalysts 2019, 9, 120. [CrossRef] 
24. Cui, J.D.; Sun, L.M.; Li, L.L. A simple Technique of Preparing Stable CLEAs of Phenylalanine Ammonia Lyase Using Co-aggregation with Starch and Bovine Serum Albumin. Appl. Biochem. Biotechnol. 2013, 170, 1827-1837. [CrossRef]

25. Shah, S.; Sharma, A.; Gupta, M.N. Preparation of cross-linked enzyme aggregates by using bovine serum albumin as a proteic feeder. Anal. Biochem. 2006, 351, 207-213. [CrossRef]

26. Nadar, S.S.; Rathod, V.K. Magnetic macromolecular cross linked enzyme aggregates (CLEAs) of glucoamylase. Enzyme Microb. Technol. 2016, 83, 78-87. [CrossRef]

27. Schoevaart, R.; Wolbers, M.W.; Golubovic, M.; Ottens, M.; Kieboom, A.P.G.; van Rantwijk, F.; van der Wielen, L.A.M.; Sheldon, R.A. Preparation, Optimization, and Structures of Cross-Linked Enzyme Aggregates (CLEAs). Biotechnol. Bioeng. 2004, 87, 754-762. [CrossRef]

28. Nguyen, L.T.; Seow, N.; Yang, K.L. Hollow cross-linked enzyme aggregates (h-CLEA) of laccase with high uniformity and activity. Colloids Surf. B Biointerfaces 2017, 151, 88-94. [CrossRef]

29. Talekar, S.; Shah, V.; Patil, S.; Nimbalkar, M. Porous cross linked enzyme aggregates (p-CLEAs) of Saccharomyces cerevisiae invertase. Catal. Sci. Technol. 2012, 2, 1575-1579. [CrossRef]

30. Galvis, M.; Barbosa, O.; Ruiz, M.; Cruz, J.; Ortiz, C.; Torres, R.; Fernandez-Lafuente, R. Chemical amination of lipase B from Candida antarctica is an efficient solution for the preparation of crosslinked enzyme aggregates. Process Biochem. 2012, 47, 2373-2378. [CrossRef]

31. Tutar, H.; Yilmaz, E.; Pehlivan, E.; Yilmaz, M. Immobilization of Candida rugose lipase on sporopollenin from Lycopodium clavatum. Int. J. Biol. Macromol. 2009, 45, 315-320. [CrossRef] [PubMed]

32. Talekar, S.; Pandharbale, A.; Ladole, M.; Nadar, S.; Mulla, M.; Japhalekar, K.; Pattankude, K.; Arage, D. Carrier free co-immobilization of alpha amylase, glucoamylase and pullulanase as combined cross-linked enzyme aggregates (combi-CLEAs): A tri-enzyme biocatalyst with one pot starch hydrolytic activity. Bioresour. Technol. 2013, 147, 269-275. [CrossRef] [PubMed]

33. Zheng, T.; Bott, S.; Huo, Q. Techniques for Accurate Sizing of Gold Nanoparticles Using Dynamic Light Scattering with Particular Application to Chemical and Biological Sensing Based on Aggregate Formation. ACS Appl. Mater. Interfaces 2016, 8, 21585-21594. [CrossRef] [PubMed]

34. Asgher, M.; Bashir, F.; Iqbal, H.M.N. Protease-based cross-linked enzyme aggregates with improved catalytic stability, silver removal, and dehairing potentials. Int. J. Biol. Macromol. 2018, 118, 1247-1256. [CrossRef]

35. Mahmod, S.S.; Yusof, F.; Jami, M.S.; Khanahmadi, S.; Shah, H. Development of an immobilized biocatalyst with lipase and protease activities as a multipurpose cross-linked enzyme aggregates (multi-CLEA). Process Biochem. 2015, 50, 2144-2157. [CrossRef]

36. Sheldon, R.A. Characteristic features and biotechnological applications of cross-linked enzyme aggregates (CLEAs). Appl. Microbiol. Biotechnol. 2011, 92, 467-477. [CrossRef]

37. Migneault, I.; Dartiguenave, C.; Bertrand, M.J.; Waldron, K.C. Glutaraldehyde: Behavior in aqueous solution, reaction with proteins, and application to enzyme cross-linking. Biotechniques 2004, 37, 790-802. [CrossRef]

38. Talekar, S.; Joshi, A.; Joshi, G.; Kamat, P.; Haripurkar, R.; Kambale, S. Parameters in preparation and characterization of cross linked enzyme aggregates (CLEAs). RSC Adv. 2013, 3, 12485-12511. [CrossRef]

39. Easa, M.N.; Yusof, F.; Halim, A.A. Characterization of Cross-Linked Enzyme Aggregates (CLEA)-amylase from Zophobas morio. Int. Food Res. J. 2017, 24, 335-339.

40. Li, X.D.; Wu, J.; Jia, D.C.; Wan, Y.H.; Yang, N.; Qiao, M. Preparation of Cross-Linked Glucoamylase Aggregates Immobilization by Using Dextrin and Xanthan Gum as Protecting Agents. Catalysts 2016, 6, 77. [CrossRef]

41. Talekar, S.; Waingade, S.; Gaikwad, V.; Patil, S.; Nagavekar, N. Preparation and characterization of cross linked enzyme aggregates (CLEAs) of Bacillus amyloloquefaciens alpha amylase. J. Biochem. Technol. 2008, 43, 314-319.

42. Rehman, S.; Bhatti, H.N.; Bilal, M.; Asgher, M. Cross-linked enzyme aggregates (CLEAs) of Pencilluim notatum lipase enzyme with improved activity, stability and reusability characteristics. Int. J. Biol. Macromol. 2016, 91, 1161-1169. [CrossRef] [PubMed]

43. Xu, D.Y.; Yang, Z. Cross-linked tyrosinase aggregates for elimination of phenolic compounds from wastewater. Chemosphere 2013, 92, 391-398. [CrossRef] [PubMed] 
44. Said, Z.S.A.M.; Arifi, F.A.M.; Salleh, A.B.; Rahman, R.N.Z.R.A.; Leow, A.L.T.; Latip, W.; Ali, M.S.M. Unravelling protein-organic solvent interaction of organic solvent tolerant elastase from Pseudomonas aeruginosa strain K crystal structure. Int. J. Biol. Macromol. 2019, 127, 575-584. [CrossRef]

45. Zerva, A.; Antonopoulou, I.; Enman, J.; Iancu, L.; Rova, U.; Christakopoulos, P. Cross-Linked Enzyme Aggregates of Feruloyl Esterase Preparations from Thermothelomyces thermophilia and Talaromyces wortmannii. Calalysts 2018, 8, 208. [CrossRef]

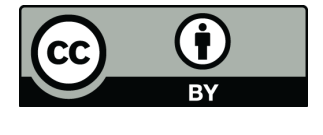

(C) 2020 by the authors. Licensee MDPI, Basel, Switzerland. This article is an open access article distributed under the terms and conditions of the Creative Commons Attribution (CC BY) license (http://creativecommons.org/licenses/by/4.0/). 